\title{
EMBA Integration: From Rhetoric To Practice
}

Charles Scott, Loyola University Maryland, USA

Frederick Derrick, Loyola University Maryland, USA

Ellen Hoadley, Loyola University Maryland, USA

\begin{abstract}
For the modern business world, business education needs to molt from the cocoon of discipline silos to the integrated business education model to train the next generation of managers. Upper management problems are rarely silo specific. Managers do things right, but leaders do the right things; and executive programs exist to build business leaders. MBA programs usually get the "business" portion of this goal right, but often do not institutionalize the "leaders" part well. This article chronicles the experiences of a major EMBA program.
\end{abstract}

Keywords: EMBA Programs; MBA Programs; Integrative Education

\section{INTRODUCTION}

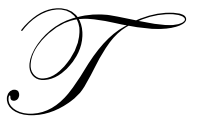

he Masters in Business Administration (MBA) degree has traditionally been a general degree in business intended to provide managers with the skills necessary to successfully manage a company. As such, MBA programs include a broad range of courses covering Marketing, Management, Operations, Accounting, and Finance, and more recently, Information Systems with additional courses in Economics, Quantitative methods, Business Law, Ethics, and International issues. Professors in these courses often have education and/or experience in only one area, and therefore they focus narrowly on a specific field of expertise. This leads to a "silo" structure, where the course builds some depth in the discipline but reinforces limited links to other disciplines, with the students expected to make the links. Pressures in the current economy push leaders to think across functional areas and to optimize the economies of scale provided by cross-functional process improvements.

In large corporations, an alternative credential is potentially available for entry and middle managementthat of the specialist. In this case, a Masters degree in one of the business disciplines--Marketing, Operations, Information Systems, Accounting, or Finance--would prepare the manager to be productive and successful in the corporation, as their job would entail only one of the areas of expertise at this stage in their career. However, promotion outside the specialist's area would come with the need to broaden one's skills to incorporate the other areas of expertise.

For executives in either large or small companies, neither the specialist degree nor the "silo" generalist degree is sufficient for success. Brunel and Hibbard (2006) notes that the best practices in business decision making must involve judgments based on system wide understanding of the connections and interdependences among the different functions of the organization. The successful executive must understand all of the disciplines sufficiently to make the strategic and trade-off decisions that he/she is required to make. The trade-off decisions typically entail more than one discipline. The successful leader cannot focus solely on one aspect of the situation. Thus, integration of the knowledge of the various disciplines is essential for success. How can programs develop students who make the leap from functional expertise to corporate leadership without an MBA program that incorporates both types of learning? Attempts have ranged from faculty intentions to discuss and incorporate these issues into existing independent classes, to extremely aggressive efforts to develop 12-20 credit-hours, team-taught courses (Geiger and Dangerfield, 1996). A third alternative would be to use a team-based management style to incorporate the various insights into decision-making. 
The market for the EMBA in the Baltimore/Washington corridor is experiencing an increase in competing providers and an evolving total market potential. As the regional market leader since first offering the EMBA in 1973, Loyola University Maryland has enjoyed a robust applicant pool and ongoing organizational support from businesses, governmental agencies, and non-profits. As economic pressures increase, students and companies demand a higher quality executive program that justifies its premium tuition over the traditional part-time MBA program. In addition, the economic pressure has led to fewer companies funding executive programs, leaving the (executive) students to self-fund, further changing the competitive environment for students. The EMBA program has been delivered by a "partners group" of faculty responsible for both curriculum design and delivery, with the intent that integration across discipline be part of the program's delivery. Historically, this theory of integration was implemented more on an ad hoc basis as individual faculty coordinated their efforts on a "one-time" basis.

The faculty partners of Loyola's EMBA program engaged in a multi-faceted curriculum review during 2009 to revise the Executive MBA program to assure that the program served the target "chief-executive-in-development." The effort started with an assessment of what the Chief Executive Officer (CEO) should be capable of doing. The most interesting component of this articulation was the realization that while traditional content areas such as marketing and operations were viewed as important knowledge, equal value was placed on less tangible and measurable skills such as building relationships and leading change. It was determined that most of the knowledge, skills and abilities (KSAs) were in the existing program but that two groups of KSA's were missing - content integration and interpersonal skill development. These two were included in our learning objectives but essentially had been left up to the students to tacitly extract from the course content and apply in a capstone project at the end of the program. ${ }^{1}$

The design effort was to develop a better conceptual MBA with only ancillary consideration as to how this program was to be implemented and who would be responsible for the various pieces. The revised EMBA program was significantly different from the previous one. It included four progressively challenging and comprehensive assignments that integrated materials covered in the cumulative whole of the course material to date at that point in the program. It also added a team coaching component. At the same time, the revised program kept a similar flow of curriculum content as the previous program and incorporated key success factors of the existing program: the initial Executive Leadership residency, an end-of-program reflective retreat, an international field study, and a domestic field study.

The specific aspect of interest in this article is the innovative method of implementing integration in the program. The thought was that integration should start early in the program to build a platform for the students to build on as they moved through the program. This was a new venture for the faculty and hence, has evolved based upon the experience we had in implementing the plan. The integration and the team coaching components were designed to integrate learning to a greater degree, to provide times for both synthesis \& development of important contemporary topics, to be more congruent to the Jesuit ideals of integration, to foster reflection and continual improvement as a person and leader to develop successful graduates, to increase and enhance the quality of the faculty/student learning partnership, to have soft as well as tangible payback potential for students and the companies in which they work, and to develop increased personal effectiveness.

\section{THE CHALLENGE: NICE IDEA - NOW HOW DO YOU IMPLEMENT IT?}

Many programs attempt to accomplish integration through an integrative "Business Policy" class at the end of the program. Others use field trips/studies to provide opportunities for this integration. Increasingly, MBA programs (especially executive programs) include an international trip as a (required or optional) part of the program to offer the opportunity to see multiple aspects of business by taking the student out of their normal context to force a broader perspective on what they experience. Athavale, Davis and Myring (2008) report on a survey of the methods that business schools used for integrating. DeMoraville, Aurand and Gordon (2000) found that although the vast majority used capstone courses for integration fewer than 5\% had a comprehensively integrated program.

\footnotetext{
${ }^{1}$ For a more complete discussion of the curriculum review process and development of the ensuing EMBA see Hoadley and Mento (2010).
} 
Part of the difficulty in implementing integration is related to the incentive system. Individual faculty members are traditionally rated on their courses alone, and integration activities come at the expense of other academic pursuits that are individually rewarded. Additionally, the entire concept of faculty load focuses effort on the number of individual courses and preps to satisfy the annual contract. Another issue is faculty turnover in the program, with individual investments of time and energy in integration potentially lost with the turnover. Another issue is the tendency of most programs--ours included--to assume that integration is the responsibility of the student. A final issue in this non-exhaustive list is the difficulty in developing activities that foster integration while not losing the "discipline-specific" rigor. Part of this relates to the necessity of both involved faculty members to understand his/her colleagues' discipline well enough for the developed exercise to foster both integration and rigor. That is, the faculty have to be able to integrate their own knowledge in order to teach integration to the students.

The original plan was for there to be an integrative assignment (IA) utilizing three class days at the end of each of the first three "semesters." " The IAs were intended to evolve with the first focused on the firm, the second on the (same) industry. The third IA was to focus on a strategic assessment of the firm. The culminating integrative activity was a "consulting project" as part of the load for the fourth and final semester. This final integrating activity was to build on the previous IAs and be implemented as an individual project at the student's own work place designing a solution to a specifically identified problem. The primary goal of the last IA was full integration of the program with the issues and work context of the student's professional life. A secondary goal was to provide a tangible project of value to the firms of the region to encourage them to send, and hopefully fund, more students in this particular program.

Although content- and presentation-related decisions are paramount to the success of integration efforts, other, more subtle issues are of equal importance. Important issues receiving little attention in the literature include the attitudes, infrastructure, and resources to successfully implement such an extensive and potentially disruptive curriculum change (Pharr, 2011). Faculty members participating in the integration level must be willing to let go of their functional "fiefdoms." Many faculty members have been trained in specialized fields of business content; they must be willing to explore content beyond those areas of specialty, including the broader domain of their functional area, as well as the other functional areas, as well as the functions of the firm, and their interactions and interdependencies with the business operations. This may result in the exposure of apparent inconsistencies and uncomfortable lack of knowledge among curricular components of the faculty. Faculty also must be aware that the integrative approach opens the educational box to the students as co-creators of learning. All of this takes a major commitment of time to acquire and understand new knowledge; openness to acquisition; and students must be aware of the benefits for the integrated orientation to the business system as a whole and to themselves. Reward systems require modification; planning time needs to be built in--time for faculty meetings to develop implementation specifics.

The change recipients, the new students, also had to be included in the communication. The incoming cohort must understand that they are part of the development and implementation, especially, but not exclusively, in the pilot year for the new curriculum, and that they are co-change implementers and recipients (Jick and Peiperl, 2003 ; 174) of the revised program. Faculty must take their role as advisors seriously, creating an interesting dynamic between students and faculty. Faculty remain the subject matter experts; students become the process experts. Faculty and students must share the responsibility willingly for mutual benefit. The explicit sharing involves multiple phases and types of communication, and a significant role adjustment for all.

\section{IMPLEMENTATION: SO HOW DID IT WORK AND WHAT DID WE LEARN?}

As we started implementing this plan, it became clear that this activity required significant coordination among the faculty implementing the project. The traditional way of teaching the courses as separate entities did not support the students' work on this integration. The faculty worked together in faculty teams over the spring semester to construct the assignments and grading rubrics for the students as well as the guiding principles for the students and faculty to construct the assignments and grading rubrics for the students as well as the guiding principles for faculty inclusion in this effort. To do this, faculty had to communicate effectively by having

\footnotetext{
2 The quote marks are present as the structure was a modified semester format with a mix of shorter courses in each semester. 
respectful conversations about their content areas to determine how their session materials contributed to the integrated application, and how they could assess their material when it was embedded in the assignment. Then the entire faculty needed to conceptualize and formulate how the four application assignments would link together over the two years. The conversations and outcomes were transformative for the program and for the faculty as they learned from each other and gained insight into the role of their discipline in the broader business context from the integration design effort. Each iteration brought new conversation to clarify what should actually happen with each integrated application. Because there was a vested interest among all to make the program work well, the energy level was high. Technology enhancements were incorporated to reduce the stressful components of program redesign. More electronic communication support was introduced to facilitate the increased integration necessary to be successful. The following lessons learned summarize our experience as we implemented the program and then, subsequently revised the design in light of what we learned.

\section{Lesson 1: Integration needs to be framed in the overall positive effect for the student, for employers, and the program.}

Comprehensive modification of the curriculum as involved in our integration process for the EMBA required acceptance and enthusiastic support from all involved -- the faculty, administration, students, and organizations that hire graduates (Heinfeldt and Wolf, 1998). Students (and faculty) often perceive integrated courses as more complex than traditional courses and are uneasy as to the evaluation process across professors and integrated disciplines. The reframing between the first and second IA primarily consisted of indicating how the IA fit into the overall plan of the program. Appendix A provides the "brickwork" of courses and activities in the program and illustrates the intent of the IA, structurally.

The program starts with a residency followed by three twelve-week semesters, each followed by a three week IA. Each semester had a common theme supporting the IA. The courses in each semester supported the theme of the subsequent IA, as they built upon the previous ones. Paralleling the courses and IAs were a sequence of experiential activities that built upon the content with an integrative application focus. The first was an International Field Study (IFS), during which the students traveled internationally to two cities to meet with a number of business executive and conduct plant tours to see how business is done outside the United States. This was followed by a Domestic Field Study (DFS) where a domestic trip is taken to visit one or more examples of successful businesses to learn what they consider their success factors to be. This was integrated with the three courses being taken in the fall of the second year-Marketing, Finance and Operations. In the spring of their second year, the students conducted a consulting project where the student teams addressed a specific problem for a company using all the skills they have developed in the program to assist the company to become more successful.

\section{Lesson 2: To be successful in our integrative approach, the faculty needed to work as a team and the students needed to work successfully in their teams.}

Teams of individuals and groups of individuals are different entities. While groups and group projects are often used in business schools, a student group is often just a collection of individuals with a task to be concluded without much defined structure. A "team" is a small number of people with complementary skills who are committed to a common purpose, performance goals, and approach for which they hold themselves mutually accountable. (Katzenbach and Smith, 1993; 45). While groups are assembled, teams are constructed and managed. With teams and team learning approach, the processes and skill sets needed for "teaming", "team building" and learning to work together are as much part of the curriculum as the deliverables linked to the assignment (Brunel and Hibbard, 2006).

Teams were used to foster cooperative learning which leads to greater skill development, greater individual achievement, and knowledge transfer. (Tinzmann et al, 1990) Each member had a measureable stake in success (learning): trouble shooting obstacles, learning from one another, developing critical thinking skills, forcing deeper contextual analysis and understanding of the problems at hand (Brunel (2006). IA teams followed Deacon-Carr et al (2005) principles of teams: teams were assigned not student self-selected; each student had to show individual proficiency in the subject matter; each student had a measurable stake in the performance of every team member; students were provided tools for coaching; and students are evaluated on coaching and counseling as well as overall team performance. 
The faculty also decided that interpersonal skill development was a key factor in leadership success and that an important context for the development and growth of those skills was in the learning teams. These teams have been an essential component of our EMBA program for many years. However, we also recognized that we were not teaching or facilitating interpersonal skills consistently and effectively across the curriculum. Additionally, coaching was more effective when provided by a professional external to the program and who did not have the additional role of grading a student's performance. Therefore, a non-faculty team coach who would guide learning teams in developing skills such as relationship building, developing influence, conflict management, negotiation, managing diversity, effectively delegating, and adaptability was added to the faculty team.

\section{Lesson 3: There needs to be a faculty coordinator of the (faculty) team designated to keep the integration design and implementation on track.}

Keeping the development process on track in one semester and then leading the implementation takes an individual well versed in leading faculty. Two structural errors were made at this stage the first year the program was delivered, including not realizing the significant role to be played by the lead faculty member of the team. The second was paying little attention to the attitudes, infrastructure, and resources to successfully implement such an extensive curriculum change (Pharr, 2011). The macro-perspective of the integrated applications was determined in the program design level. Each of the (three) IAs was given three class days totaling twenty two and half hours for the IA with the last class day for team presentation with questions and answers. This left the IA implementation details in the hands of the faculty team teaching that semester. The details ranged from determining a process as to how the integration would occur to more mundane logistical decisions (page limits, presentation scheduling, etc.) to implementing the criteria determined for grading and for student reflection about the IA experience. In addition, each member of the faculty team needed to shorten their traditional courses to create the time for the IA. While accepting the benefit of the interdisciplinary, integrative assignment, it is quite another thing to let go of a portion of their functional discipline coverage for these (less tangible) aspects.

As an example, the first IA was for each team to complete analyses of two firms-one leading in its industry and one lagging. This IA built upon the knowledge and skill set developed in the first semester and developed the skills necessary to move into the second semester. While the IA emphasized the integration of disciplines, a side effect was that professors identified and discussed integrative aspects in their courses to other disciplines more often than in prior semesters.

By engaging in the firm analyses, by the end of the IA, students were to be able to: (1) demonstrate the capabilities required to integrate business concepts to analyze the business of a firm; (2) apply the tools provided in the semester's course content to the analysis; (3) demonstrate effective team dynamics, leadership, and negotiation skills in doing the analysis (assessed through self- and inter-teammate assessment); and (4) effectively present the analysis and reflection outcomes in written and oral format.

Lesson 4: The plan for what work needs to be done by faculty and/or student teams and who will do it needs to be worked out before individual assignments can be made and accomplished for collective use; that is, before the integration effort is started. True integration occurs at the end, but is only possible if the planning provides structure and time for it.

There are many calendar issues in any effort that entails collecting data on industries or firms. Early warning of these issues is essential for there to be success in the integration, which comes after the IA is completed. In addition, the work load was high enough with three courses at a time, as well as full-time work, that the students tended to procrastinate on the IA development until the actual class days allocated to it. In addition, there were communication issues as individual faculty gave answers to technical questions that differed from other faculty. ${ }^{3}$

\footnotetext{
${ }^{3}$ A few ad hoc implementation issues that were added included the use of a common text across course that included some firm studies that were similar to the goal of the project. The different chapters dealt with firms that faced problems in different disciplines, allowing the different course instructors to use the chapter(s) that applied to their discipline in their course.
} 
Lesson 5: Business activity is very complex, and finding simple answers almost impossible. Any integration effort addressing real situation(s) entails trade-offs and uncertainty. This needs to be included in the instructions to prepare the students to seek the "best" solution rather than "the" solution.

The students were given a list of industries from which to choose and were not allowed to study the industry in which they worked. This broadened the learning process and precluded one student from becoming the "expert" and doing the majority of the work due to previous understanding of the industry- or firm-specific issues. The list was chosen by the faculty on the basis of previous faculty experience or knowledge of availability of data as well as the ability to identify - a leader firm and a laggard firm for study and contrast.

The students were required to define what constitutes success. Is it short run profit, long run profit potential, profit trend, an ethically run business, product development, firm stability, or something else? The need to define this was surprising to the students, and forced them to draw on data as well as more qualitative factors affecting the firms. At one point, one of the teams reversed which of the two firms identified they felt was the leader and which the laggard.

The fact that there were common themes across project pointed out the universal nature of these themes, which override the (silo) technical analysis which is taught in individual courses. This helps create a context and a broader perspective on the course material and broadens the interest in the courses, as they are connected to a broader reality. The page and time limits, necessary due to the number of teams and time cost of grading, actually fostered the prioritizing of issues. The short time and few pages forced the teams to choose the important issues for focused attention. The fact that there were numerous disciplines included in the exercise and that the output would be graded by experts in each forced both this prioritization and the justification of the choices made - skills that the executive needs.

\section{Lesson 6: Strategy needs to be among the courses in any early integration effort to keep the focus at the level of the executive decision-maker rather than the lower management "implementer."}

\section{Lesson 7: To be fully focused on integration, the discipline coverage in the courses needs to be completed.}

The courses included in the first semester were Corporate Social Responsibility, Managerial Accounting, Organizational Effectiveness, half of a Microeconomics course and half of a quantitative methods course. A problem arose since the students had not completed a business strategy course, and this left them focusing too narrowly in the analysis. This led to five faculty members being involved in the IA and fielding business strategy issues.

We provided the students with examples of course specific questions to address in the IA product and a rubric for evaluation of the presentation, written report and after action (personal and team) reflections. The half courses were present due to a scheduling choice that the IA should be mid-year, but the program is structured along a quarter system schedule. This led to significant student and faculty dissatisfaction about these two courses being split, as the students had difficulty with continuity between the two halves of the courses.

The first IA attempted was subject to Murphy's Law on steroids. Some of the problems were design related, some nature related, and some specific personnel related. In addition, the faculty needs to be in accord as to what the IA output "should" look like and what the parameters should be. There was a page limit, but there was inconsistent feedback about whether this limit would be enforced, and the limit was implemented selectively by the faculty as they graded the violations that occurred. The question and answer session was not particularly effective, as the projects were not completed early enough for faculty to have read them prior to the presentations. In addition, due to this lateness, there was limited ability on the faculty's part to give effective constructive feedback in the development stage, which the students could use for improving the final product. This was partially due to the schedule of the IA such that it straddled the Christmas break (a design issue), and the fact that the first scheduled IA day was snowed out (an act of God). Thus, the initial work had to be done virtually, without the plan being worked out beforehand. 
Due to the lack of careful (both faculty and student team) prior planning, much of the effort was last minute with corners having to be cut and with no ability to do effective revisions. The presentations and written products were close to first draft status, resulting in a fairly high variance in the quality of the presentations and written reports. Group projects typically consist of a combination of group and individual effort requiring an initial (group) plan mutually agreed upon followed by individual efforts. The individual effort phase is then followed by team assimilation and interpretation of the individually acquired input. When this process is condensed, the integration is not as comprehensive as it should be. The second year, the two half courses were recombined, and strategy was added to the courses presented as preparation for the IA.

\section{Lesson 8: The deadlines for the first draft of the written reports should be well ahead of the presentation and submission deadline to allow time for effective feedback and revision.}

One other design issue that became very clear as the first and then the second IA were implemented is that too much time had been allocated to the drafting of the papers. The idea was that one whole day was to be devoted to the presentations, so there needed to be two weeks to develop the reports. In the spring, nature intervened again, cutting the time available. Due to this, we rescheduled the courses to account for the lost class time, but in the process, introduced a partial day earlier in the semester for the prior planning necessary to structure and allocate the (individual) work necessary to amass the input necessary for the integration to take place.

Having been through the initial IA, the students effectively used the time for planning and most teams developed the drafts early enough for specific faculty input and revision. The IA2 presentations and reports were significantly better than the IA1 outcomes. In addition, the students had more course content upon which to base their integration. This led to more insight, with less reporting and more interpretation. The second IA was intended to address the industry in which their two firms in IA1 were participants. This gave the opportunity to increase the depth of analysis, as some of the earlier data collection, and insights were applicable on a broader scale.

The second aspect was collecting data. This entailed determining what data to collect. In today's information age, the problem is typically not the lack of data, but that of information overload, with specific critical data missing. Having to face this difficulty and the cost/benefit of data collection was a good (if frustrating) learning experience. In addition, culling the data for insight, using the filters from all of the courses served to broaden the students' perspectives and strengthen the team skills.

The process, as structured, allowed the teams to develop drafts for review by the faculty in time for revision in light of the suggestions. This led to significant restructuring between first and second draft and led to the presentations and subsequent discussion being significantly better than the previous year's experience. In addition, these presentations were videotaped, allowing the students to view themselves and learn from what they saw.

A team and individual reflection was required, subsequent to the faculty feedback on the presentations and papers. This allowed the faculty to comment on how well the students handled the details of the project within the context of the material the faculty member taught, but also how well they integrated this material with the other disciplines. There was also the opportunity for individual student (constructive) feedback to the other teams and individuals based upon the presentations.

One of the biggest improvements observed was in the type and depth of the discussion following each presentation. The class was involved in their colleagues' presentations and actively trying to learn from the presentations and the contrast of what the various teams found. It was also instructive that many of the same issues came up with each presentation, with corporate culture, stability, and leadership being key commonalities across issue identified with all projects. 
Lesson 9: Faculty learns as much about integration as the students do, so incorporate this as a teaching feature rather than a time waster. This integration is both about the context of business and the pedagogies of instruction. This also should be taken into account as decisions are made about faculty continuity within the executive program.

Students entered the IA opportunities with uneasiness, stress, and lack of clarity as to how to frame and approach the deliverables. In turn, they ended with faith in their ability to resolve a multifaceted business problem, greater appreciation for the intricacies of the working of teams, greater knowledge of each discipline, and a significant understanding of how the pieces of the business puzzle fit together, intersected each other, and for depth. Writing and communication skills of the final products were noticeably stronger than in prior papers with improvements noted by both students and faculty. The students recognized that business is more than the sum of the individual disciplines. In turn, the faculty learned more about other disciplines and their interactions. The faculty initially thought the intent was not to supplant the traditional business material but to present the functional principles in an integrated and coordinated fashion. We learned that tradeoffs had to be made to cover the functional material and to cover the goal of cross functional integration. We became better business educators in the process. One interesting question is how to institutionalize this (faculty) learning so that it is not lost when there is turnover of faculty teaching in the program.

Figure 1 illustrates the intended integration by showing the framing of the whole program, including the positioning and role of the one IA retained in the revised program. The layers indicate the levels of activity (both conceptually, and in time) and the cumulative nature of the design in the program. This figure was presented to the students in the second year of implementation early in the program to help them conceptualize the role of the various elements in the program design and how each contributed to their eventual management capabilities.

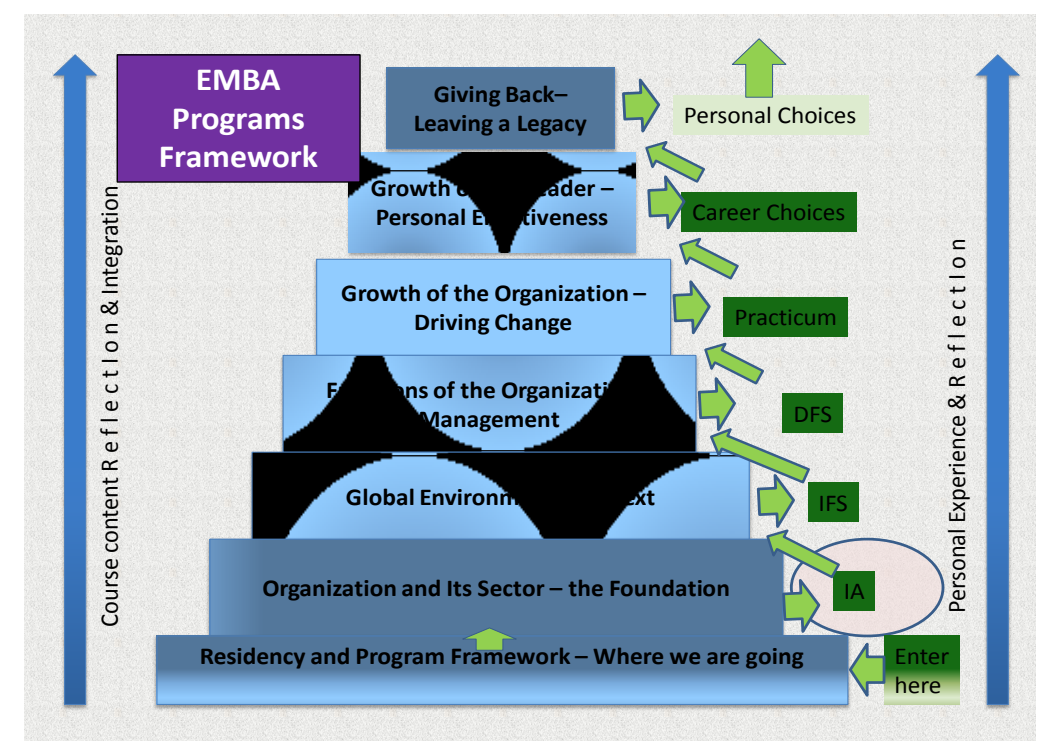

Figure 1: Conceptual Design for an Integrated Executive MBA Program

The program starts with a residency followed by two ten-week modules laying the foundation of the firm and its context. The layers indicated the themes of the content in the courses as they built upon the previous ones. Parallel to the courses is a sequence of experiential activities that build upon the content and integrate what was learned. The first is the IA. The second experiential aspect of the program is an International Field Study (IFS), during which the students travel internationally to two cities to meet with a number of business executive and conduct plant tours to see how business is done outside the United States. This is followed by a Domestic Field Study (DFS) where a domestic trip is taken to visit one or more examples of successful businesses to learn what they consider their success factors to be. This was integrated with the three courses being taken in the fall of the second 
year-Marketing, Finance and Operations. In the spring, the students conduct a consulting project where the student teams address a specific problem for a company using all the skills they have developed in the program to assist the company to become more successful.

\section{CONCLUSION}

For the modern business world, business education needs to molt from the cocoon of discipline silos to the integrated business education model to train the next generation of managers. Upper management problems are rarely silo specific. Managers do things right, but leaders do the right things; and executive programs exist to build business leaders. MBA programs usually get the "business" portion of this goal right, but often do not institutionalize the "leaders" part well.

Integration recognizes this important aspect and works to prepare a successful manager. The issue is the lack of understanding of the interrelationships among the separate fields of business on which most majors are based. The ability to combine disparate information to draw insight is an important skill, especially for CEOs. This IA project forced integration by choosing rubrics that crossed discipline and that were used by the entire faculty involved. The faculty worked together to develop the rubric and the guidelines (page limits, presentation limits, etc.). In the process, they were forced to become familiar with the content of the other courses included in the IA. During the IA, there was considerable communication between the students and the faculty as the students collected and interpreted the data. ${ }^{4}$

Student feedback indicated that the teams were forced to work together more effectively, teaching teamwork as well. The down-side was that the extent of learning and additional ability to integrate was at a high time and work cost. The faculty all graded the presentations and written reports. With five faculty members doing the grading, this activity is time-intensive on the faculty's part. To normalize the grades, the highest and lowest were dropped on each aspect graded. This was done primarily due to specific faculty taking a more (or less) critical view on the adherence to the specific guidelines for the presentations and reports. However, it does also allow for the fact that individual faculty will react to different aspects of the report due to their own discipline-specific expertise. Thus, there will be an inherently high variance in the grading.

Subsequent to this experience, it was decided to reposition IA1 and do away with IA2 and IA3, as the benefit was not worth the cost, given the intensity of the program and the limited time available for course instruction. The IA3 was replaced by some more intensive attention to narrow topics that the students had expressed interest in and in which the faculty had an expertise. This allowed increasing the depth in a program that was otherwise a generalist degree.

The second year, the IA was positioned at the second quarter break, eliminating the split courses and including a strategy course in the mix of courses that was covered by the IA. In addition, the strategy course paid explicit attention to the IA projects, using the preliminary work on the integration as a focus for application of the strategy tools being covered. With these changes and some effort to better frame the intent of the IA as part of an overall plan and evolution of the learning process in the program, the IA was successful as a learning exercise for both students and faculty as greater appreciation for the interdependencies and a better understanding of their intricacies evolved.

\section{AUTHOR INFORMATION}

Charles E. Scott is a Professor of Economics, Loyola University Maryland. He has thirty four years of teaching experience in a Jesuit business school at the undergraduate, MBA and Executive MBA levels, as well as teaching at Tallinn Technical University in Estonia and Bilkent University in Turkey. Twenty eight professional publications including in Economica, National Tax Journal, Public Finance Quarterly, and Behavioral Economics, covering state tax, prison industry, housing privatization, and labor economics issues. E-mail: cscott@Loyola.edu. Corresponding author.

\footnotetext{
${ }^{4}$ Copies of the course syllabus and grading rubrics are available from the authors.
} 
Frederick W. Derrick is Professor of Economics at Loyola University Maryland. His teaching and research interest are in applied microeconomics and applied statistics. Teaching experience ranges from freshmen with undeclared majors to doctorate students and their theses. Over 30 professional publications including publications in Economica, Journal of Housing Economics, Southern Economic Journal, Journal of Business and Economic Statistics, Health Care Management Review, Health Services Research, Public Finance Quarterly, Advances in Taxation, and Journal of Consumer Research. Presentations have been made to a wide range of professional meetings and government hearings. E-mail: FDerrick@loyola.edu.

Ellen D. Hoadley is Professor of Management Information Systems at Loyola University Maryland. Dr. Hoadley teaches Information Technology and Strategy in the MBA and Executive MBA programs, as well as Systems Analysis and Design at the undergraduate level. Her research areas include evaluation of the business value of IS, business process reengineering, requirements determination in systems analysis, and the use of color in the human/computer interface. Dr. Hoadley has published in journals such as Communications of the ACM , DATA BASE for Advances in Information Systems, Journal of Business and Economic Perspectives, and Journal of Knowledge and Process Management. E-mail: ehoadley@loyola.edu.

\section{REFERENCES}

1. Athavale, M., Davis, R. and Myring, M. (2008) The integrated business curriculum: an examination of perceptions and practices. Journal of Education for Business, 83(5), pp295-301.

2. Brunel, Frederic F. and Hibbard, Jonathan D. (2006) Using innovation in student teaming to leverage crossfunctional and marketing learning: evidence from a fully integrated undergraduate core. Marketing Education Review, 16(3) pp.15-23.

3. Deacon-Carr, S. Herman, E.D., Keldsen S.Z., Miller, J.G. and Wakefield, P.A. (2005) The team learning assistant workbook. New York: McGraw Hill.

4. DeMoranville, C., Aurand T.W. and Gordon, G.L. The delivery of an undergraduate, cross-functional business principles program: one university's continuing journey. Marketing Education Review 10(3), pp29-41.

5. Geiger, J. J. and Dangerfield, B.J. (1996) An analysis of integrated curriculum models in U.S. colleges of business. Proceedings of the Decision Sciences Annual Meeting.

6. Heinfeldt, J. and Wolf, F (1998) Re-engineering the business curriculum: a stakeholder paradigm. Journal of Education for Business, 73(4): pp198-203.

7. Hoadley, E.D. and Mento, A.J. (2010) Integrating the executive MBA curriculum: tales of the cat herder. American Journal of Business Education, 3(4): pp 91-98.

8. Jick, T. D., and Peiperl, M. A. (2003). Managing change: Cases and concepts. Second edition. McGrawHill, Boston, MA.

9. Katzenbach, J.R. and Smith, D.K. (1993) The wisdom of teams: creating the high-performance organization. Boston, MA: Harvard University Press.

10. Pharr, S.W. (2011) Foundational considerations for establishing an integrated business common core curriculum. Journal of Education for Business, 76(1), pp.20-23.

11. Pozner, Barry Z., (2008) The future is now. BizEd, May/June 2008, pp. 24-34.

12. Tinzmann, M.B. and Jones, B.F., Fennimore, T.F., Bakker, J., Fine, C. and Pierce, J. (1990) What is the collaborative classroom? Oak Brook: North Central Regional Library. 


\section{APPENDIX A}

Executive MBA Curriculum 2010 - Program Plan: What do CEOs do? (Program Themes: Globalization, Growth, Leadership, Innovation, and Strategic Thinking)

\begin{tabular}{|c|c|c|c|c|}
\hline \multicolumn{2}{|c|}{ Fall/ Year 1} & \multicolumn{3}{|c|}{ Focus: The Firm - Tools and Basics } \\
\hline \multirow{4}{*}{$\begin{array}{l}\text { Residency } \\
(2.5 \mathrm{cr})\end{array}$} & Wk 1-8 & Wk 9-12 & Wk 13- 14 & Wk 15 \\
\hline & Ethics \& Corporate Social Responsibility $(2.0$ cr $)$ & Micro-economics & \multirow{3}{*}{$\begin{array}{l}\text { Integrated } \\
\text { Application } \\
\text { \#1 }(2.0 \mathrm{cr})\end{array}$} & \multirow[t]{2}{*}{ Presentations } \\
\hline & Financial \& Managerial Accounting $(3.0 \mathrm{cr})$ & & & \\
\hline & Leadership \& Organizational Effectiveness $(2.0 \mathrm{cr})$ & Decision Making Tools & & Synthesis \\
\hline
\end{tabular}

\begin{tabular}{|l|l|l|l|}
\hline Spring/ Year 1 & \multicolumn{2}{|c|}{ Focus: The Industry - Competitive Analysis } \\
\hline Wk 1-4 & Wk 5-12 & Wk 13-14 & Wk 15 \\
\hline Micro-economics $(2.0 \mathrm{cr})$ & Macro-economics $(2.0 \mathrm{cr})$ & $\begin{array}{l}\text { Integrated } \\
\text { Application }\end{array}$ & Presentations \\
\cline { 1 - 2 } Strategy Formulation $(1.0 \mathrm{cr})$ ) & Government \& Legal Environments $(2.0 \mathrm{cr})$ & Synthesis \\
\hline Decision Making Tools $(2.0 \mathrm{cr})$ & Global Business $(2.0 \mathrm{cr})$ & $\mathrm{cr})$ & \\
\hline
\end{tabular}

\begin{tabular}{|c|c|c|c|c|}
\hline \multicolumn{2}{|c|}{ Fall/ Year 2} & \multicolumn{3}{|c|}{ Focus: What Are Organizations Doing? Opportunity Identification } \\
\hline \multirow{4}{*}{$\begin{array}{l}\text { IFS } \\
(2.5 \\
\text { cr })\end{array}$} & Wk 1 & Wk 2-12 & Wk 13-14 & Wk 15 \\
\hline & Team & Strategic Marketing $(2.5 \mathrm{cr})$ & \multirow{3}{*}{$\begin{array}{l}\text { Integrated } \\
\text { Application } \\
\# 3(2.5 \mathrm{cr})\end{array}$} & \multirow[t]{2}{*}{ Presentations } \\
\hline & Development & Strategic Finance $(2.5 \mathrm{cr})$ & & \\
\hline & $(1.0 \mathrm{cr})$ & Strategic Operations $(2.5 \mathrm{cr}$ & & Synthesis \\
\hline
\end{tabular}

\begin{tabular}{|l|l|l|l|l|l|}
\hline Spring/ Year 2 & Wocus: What Should Organizations Do? Solution Identification and Change Planning \\
\hline Wk 1-5 & Wk 6-8 & Wk 9-12 & Wk 13 & Wk 14 & Wk 15 \\
\hline Information Technology $(2.0 \mathrm{cr})$ & $\begin{array}{l}\text { Integrated } \\
\text { Application \#4 } \\
(5.0 \mathrm{cr})\end{array}$ & Presentations & Presentations & Retreat \\
$(1.0 \mathrm{cr})$
\end{tabular}


NOTES 